\title{
Shear bond strength of ceramic brackets after different pre-treatments in porcelain surface
}

\author{
Naudy Brodbeck May ${ }^{1}$, Élito Araújo ${ }^{2}$, Luiz Clovis Cardoso Vieira ${ }^{2}$ \\ ${ }^{1}$ Universidade do Sul de Santa Catarina - UNISUL, School of Dentistry, Department of Orthodontics, Palhoça, SC, Brazil \\ 2Universidade Federal de Santa Catarina - UFSC, School of Dentistry, Department of Orthodontics, Florianópolis, SC, Brazil
}

\begin{abstract}
Aim: To evaluate the bond strength of brackets bonded after different surface treatments on two dental ceramics. Methods: One hundred and twenty discs ( $5 \mathrm{~mm}$ thick and $7 \mathrm{~mm}$ diameter) of two ceramic types were made and randomly divided in 8 groups. Groups 1, 3, 5, and 7 used Eris ceramic and groups 2, 4, 6, and 8 used d.Sign ceramic. The ceramic surfaces were treated with 10\% hydrofluoric acid (G1 and G2), 10\% hydrofluoric acid + silane (G3 and G4), aluminum oxide blasting + 35\% phosphoric acid + silane (G5 and G6), CoJet blasting + 35\% phosphoric acid + silane (G7 and G8). Metallic brackets were cemented with Concise cement. Mechanical test was performed in a universal testing machine until failure. Results: The average values (MPa) obtained (G1 - 7.30; G2 - 6.12; G3 - 17.49; G4 - 19.54; G5 - 18.80; G6 - 21.93; G7 - 6.81 e G8 - 9.77) were submitted to ANOVA and Tukey test $(p<0.05)$. The fracture patterns were analyzed in stereoscopic microscope $\left(25^{\prime} X\right)$ and representative samples of each group were analyzed in SEM. Conclusions: It was possible to conclude that use of silane after hydrofluoric acid increased the bond strength values.
\end{abstract}

Keywords: adhesives; dental bonding; dental porcelain; orthodontic brackets; shear strength.

\section{Introduction}

The advances in cosmetic dentistry and the increased aesthetic requirements have led to a growing demand for orthodontic treatments ${ }^{1-4}$ and orthodontists have sometimes to deal with patients that ceramic laminates or crowns from previous dental interventions ${ }^{3-5}$. It is known that the orthodontic treatment will be successful only if there is an adequate bond strength between the substrate (tooth, ceramic, or ceromer) and the orthodontic appliance (bracket); notwithstanding, the bond strength between ceramic/brackets has proven to be unsatisfactory ${ }^{1,3-6}$.

Buonocore $^{7}$ (1955) reported that it was possible to bond the resin to the tooth based on a study about enamel. Ever since, several researches have been performed aiming to establish a clinical protocol for the bonding procedure using other substrates like dentin, metal, composite and ceramic ${ }^{8-9}$. As regards ceramics,

Received for publication: January 22, 2015 Accepted: March 04, 2015

Correspondence to: Naudy Brodbeck May Rua Vitor Konder, 66 Ap 900 CEP: 88.015-400 - Florianópolis, SC, Brasil Phone: +55 4896405776 E-mail: naudy.may@unisul.br due to their different compositions, diverse methods have been developed for the treatment of their surfaces ${ }^{10-11}$.

Different pretreatment methods have been proposed for substrates that will receive orthodontic brackets, as polishing with sandpapers ${ }^{2,12}$, creation of irregularities with diamond burs ${ }^{2,6}$, laser ${ }^{13}$, hydrofluoric acid etching ${ }^{3,5,12}$, aluminum oxide blasting ${ }^{2-3,6}$, phosphoric acid etching ${ }^{5,13}$, maleic acid etching ${ }^{13}$, acidulated phosphate fluoride application ${ }^{2,12}$, silane agent application ${ }^{2,4-5,12}$, and lastly, the combination of one of the above-mentioned treatments with or without silane 
application ${ }^{4-6}$. However, failures have been normaly found when a bracket is cemented to a ceramic restoration ${ }^{1,3-6}$.

Considering the lack of conclusive studies regarding the most effective pretreatment technique for bonding orthodontic appliances to teeth with ceramic prosthesis, the aim of this study was to evaluate the bond strength of brackets bonded after different surface treatments on two dental ceramics. The null hypothesis is that there are no significant differences among pre-treatment with $10 \%$ hydrofluoric acid, $10 \%$ hydrofluoric acid with silane agent, aluminum oxide blasting with $35 \%$ phosphoric acid and silane and CoJet blasting with $35 \%$ phosphoric acid and silane.

\section{Material and methods}

For this study were made 60 discs for each ceramic (Eris (Ivoclar Vivadent, Schaan, Liechtenstein) and d.Sign (Ivoclar Vivadent)) using a plastic matrix $(5 \mathrm{~mm}$ thick and $7 \mathrm{~mm}$ diameter). The specimens were embedded in PVC tubes (Amanco, São Paulo, SP, Brazil), with $20 \mathrm{~mm}$ external diameter by $20 \mathrm{~mm}$ height. The PVC tubes were filled with polystyrene resin (Central Fiberglass, Florianópolis, SC, Brazil), prepared according to manufacturer's recommendations. For easier identification of the groups, different pigmentations (Clássico, São Paulo, SP, Brazil) of polystyrene resin were used for each group. Then they were divided into 8 groups $(n=15)$ according to the surface treatment and type of ceramic (Table 1).

For G1 and G2, the surface treatment was $10 \%$ hydrofluoric acid for $20 \mathrm{~s}$, rinse for $15 \mathrm{~s}$ and $10 \mathrm{~s}$ drying. For G3 and G4 the same procedures were performed plus the application of 3 layers of silane agent, dryed for $15 \mathrm{~s}$ and photo-activated for $10 \mathrm{~s}$. In G5 and G6, the aluminum oxide blasting was performed during $15 \mathrm{~s}$, with pressure at $80 \mathrm{psi}$ (using a needle gauge to measure pressure) at a $5 \mathrm{~mm}$ distance; $35 \%$ phosphoric acid etching for $30 \mathrm{~s}$, rinsing during $15 \mathrm{~s}$, drying for $10 \mathrm{~s}$, application of 3 layers of silane agent, drying during $15 \mathrm{~s}$ and photo-activation during $10 \mathrm{~s}$. At last, the specimens of G7 and G8, after the same previous procedures as in G5 and G6, were blasted by the CoJet system followed by application of $35 \%$ phosphoric acid for $30 \mathrm{~s}$ and 3 layers of silane agent.

Concise cement (3M ESPE, St Paul, MN, USA) was prepared according to the manufacturer's instructions and

Table 1. Groups according to the pre-treatment and the type of ceramic.

\begin{tabular}{lll}
\hline Surface treatment & $\begin{array}{l}\text { Eris } \\
\text { Ceramic }\end{array}$ & $\begin{array}{l}\text { d.Sign } \\
\text { Ceramic }\end{array}$ \\
$10 \%$ hydrofluoric acid & G1 & G2 \\
\hline $\begin{array}{l}10 \% \text { hydrofluoric acid } \\
+ \text { silane agent }\end{array}$ & G3 & $\mathrm{G} 4$ \\
\hline $\begin{array}{l}\text { Aluminum oxide blasting } \\
+35 \% \text { phosphoric acid } \\
+ \text { silane agent }\end{array}$ & $\mathrm{G} 5$ & $\mathrm{G} 6$ \\
\hline $\begin{array}{l}\text { CoJet blasting } \\
+35 \% \text { phosphoric acid }\end{array}$ & & \\
+ silane agent & $\mathrm{G} 7$ & $\mathrm{G} 8$ \\
\hline
\end{tabular}

inserted on the specimen's surface. Next, using tweezers (Dental Morelli Ltda, Sorocaba, SP, Brazil), standard metallic brackets (Dental Morelli) for central incisors, with area of $6.08 \mathrm{~mm}^{2}$, were positioned at the center of ceramic blocks with manual pressure. The excess resin was removed using explorer catheter (Duflex - SS White Group, Gloucester, UK).

The ceramic/bracket specimens were stored in an oven (QUIMIS, model Q317B, Diadema, SP, Brazil) at $37{ }^{\circ} \mathrm{C}$ immersed in distilled water for $24 \mathrm{~h}$. After that, the specimens were subjected to 800 thermal cycles (Ética Equip. Cient. S.A., series 96, no 0364, model 521-E, São Paulo, SP, Brazil), for $30 \mathrm{~s}$ at 5 ${ }^{\circ} \mathrm{C}$ and $30 \mathrm{~s}$ at $55 \mathrm{C}$, with $10 \mathrm{~s}$ dell-time between baths.

The shear strength test was performed in a universal testing machine (Instron model 4444, Canton, MA, USA), at a cross-speed of $0.5 \mathrm{~mm} / \mathrm{min}$. The specimens were positioned in a metallic glove ( $20.5 \mathrm{~mm}$ diameter x $20 \mathrm{~mm}$ high). The test was performed using a chisel as load on the ceramic/ bracket interface, trying to simulate the oral cavity environment, as well as the masticatory loads.

The fracture patterns produced after the shear test were observed with a stereomicroscope (XLT30, Nova Optical Systems, Piracicaba, SP, Brazil) at $25 \times$ magnification, and classified according to Vaz et al. ${ }^{14}$ (2011) as: (1) adhesive fracture: cement/bracket; (2) adhesive fracture: ceramic/ cement; (3) mixed fracture: cement/bracket; (4) mixed fracture: ceramic/bracket/cement. Representative specimens of each group were randomly selected to determine the fracture pattern in a scanning electron microscope (Philips XL-30, Mahwah, NJ, USA) set at $20 \mathrm{kV}$. SEM micrographs were obtained at $15 \times$ and $60 \times$ magnifocations.

The shear strength data were subjected to two-way ANOVA and Tukey's test for multiple comparisons $(p=0.05)$. Fracture pattern data were analyzed statistically by KruskalWallis test $(p=0.05)$. Paiwise comparisons of groups were performed with Mann-Whitney $U$ test $(p=0.05)$. The correlation between shear strength and fracture pattern was performed by Spearman's rank correlation.

\section{Results}

ANOVA showed that there were statistically significant differences among the ceramics $(p=0.01)$ and surface treatments $(p=0.0001)$, but it did not show interaction among them $(p=0.14)$. Means compared by the Tukey's test $(p<0.05)$ are described in Table 2. Faiure mode analysis is described in Table 3.

Table 2. Bond strength means and standard deviations.

\begin{tabular}{lcc}
\hline Groups & Mean $(\mathrm{MPa})$ & Standard deviation \\
G1 & $7.30^{\mathrm{a}}$ & 3.5043 \\
$\mathrm{G} 2$ & $6.12^{\mathrm{a}}$ & 3.1490 \\
G3 & $17.49^{\mathrm{b}}$ & 3.9677 \\
G4 & $19.54^{\mathrm{b}}$ & 4.3325 \\
G5 & $18.80^{\mathrm{b}}$ & 4.9050 \\
G6 & $21.93^{\mathrm{b}}$ & 4.6884 \\
G7 & $6.81^{\mathrm{a}}$ & 2.4816 \\
G8 & $9.77^{\mathrm{a}}$ & 4.5717
\end{tabular}

Same letter indicate statistically significant difference between them (Tukey test, $p<0.05$ ) 
Table 3. Distribution in percentiles of fracture standards after shear test.

\begin{tabular}{|c|c|c|c|c|}
\hline \multirow[t]{2}{*}{ Groups } & \multicolumn{4}{|c|}{ Fracture standard (\%) } \\
\hline & $\begin{array}{l}\text { Adhesive } \\
\text { (cement/bracket) }\end{array}$ & $\begin{array}{l}\text { Adhesive } \\
\text { (ceramic/cement) }\end{array}$ & $\begin{array}{l}\text { Mixed } \\
\text { (cement/bracket) }\end{array}$ & $\begin{array}{l}\text { Mixed } \\
\text { (cement/bracket/ ceramic) }\end{array}$ \\
\hline G1 & 0 & 100 & 0 & 0 \\
\hline G2 & 0 & 100 & 0 & 0 \\
\hline G3 & 46.66 & 0 & 53.33 & 0 \\
\hline G4 & 0 & 60 & 40 & 0 \\
\hline G5 & 33.33 & 0 & 6.66 & 60 \\
\hline G6 & 26.66 & 0 & 6.66 & 66.66 \\
\hline G7 & 93.33 & 0 & 6.66 & 0 \\
\hline G8 & 100 & 0 & 0 & 0 \\
\hline
\end{tabular}

Initially, the groups were compared relative to the fracture pattern scores by the Kruskal-Wallis test $(H=52.49$; $\mathrm{p}<0.0001)$. In the Mann-Whitney $U$ test, the groups were compared in a pairwise fashion (Table 4). The Table 4 indicates significance values between the groups that did not present statistical difference related to ceramics.

Table 4. Comparisons of fracture patterns by Mann-Whitney U test.

\begin{tabular}{llc}
\hline $\begin{array}{l}\text { Comparisons among } \\
\text { the groups }\end{array}$ & $\mathbf{U}$ & $\mathbf{p}^{*}$ \\
G1XG2 & 112.500 & 1 \\
G3XG4 & 96.000 & 0.460419 \\
G5XG6 & 104.500 & 0.695646 \\
G7XG8 & 105.000 & 0.317310 \\
\hline
\end{tabular}

*Statistically significant difference $(p<0.05)$.

The Spearman's rank correlation showed that the higher the bond strength value, the more severe the fracture pattern, including fracture of ceramic or bracket $(\mathrm{R}=0.372$; $\mathrm{p}<0.0001)$.

SEM micrographs (Figures 1, 2, 3 and 4) illustrate representative fracture patterns found in each group.

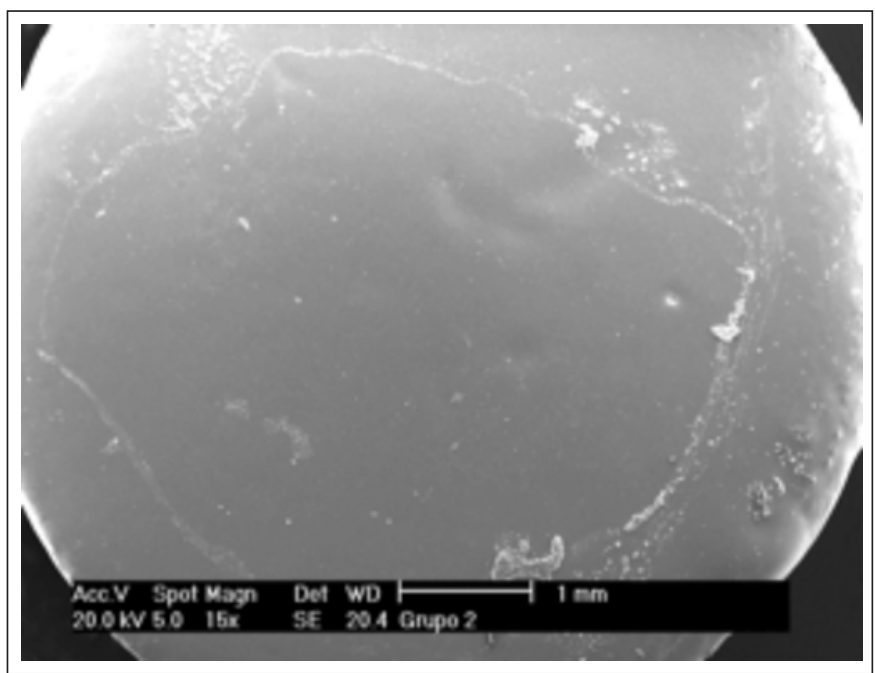

Fig. 1. Fracture pattern in $\mathrm{G} 1$ and $\mathrm{G} 2$ after shear test (Adhesive ceramic/cement).

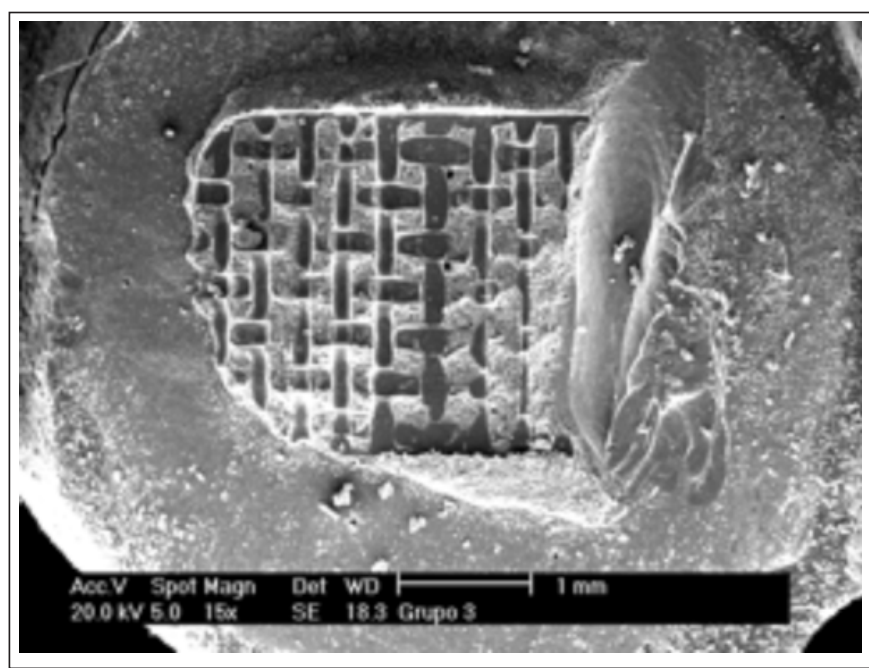

Fig. 2. Fracture pattern in $\mathrm{G} 3$ and $\mathrm{G} 4$ after shear test (Mixed cement/bracket).

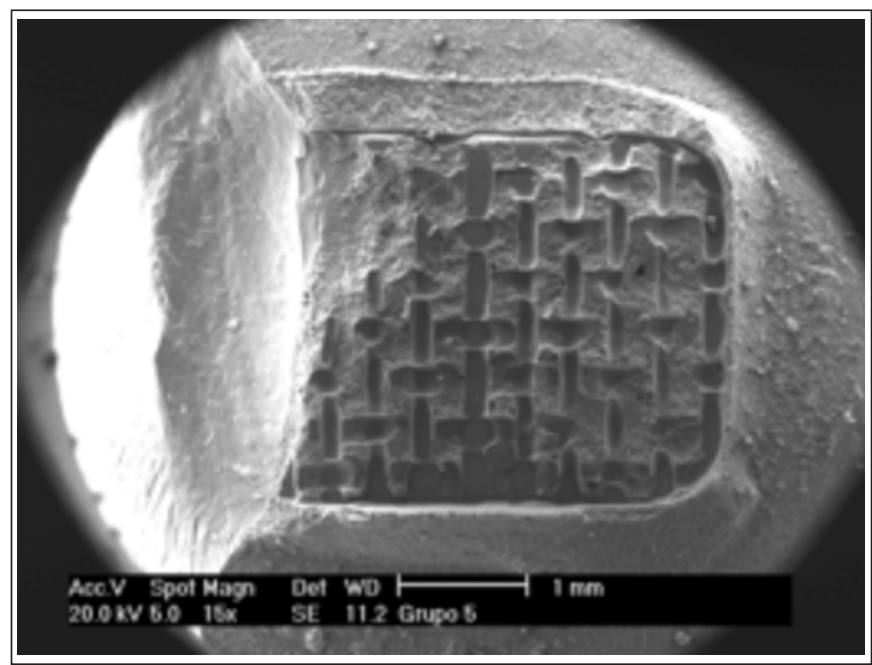

Fig. 3. Fracture pattern in G5 and G6 after shear test (Mixed cement/bracket/ ceramic).

\section{Discussion}

Based on the results of this study, the null hypothesis that there are no significant differences among the different ceramics treatments was rejected. The use of $10 \%$ hydrofluoric acid alone produced lower bond strength values (G1 - 7.30 


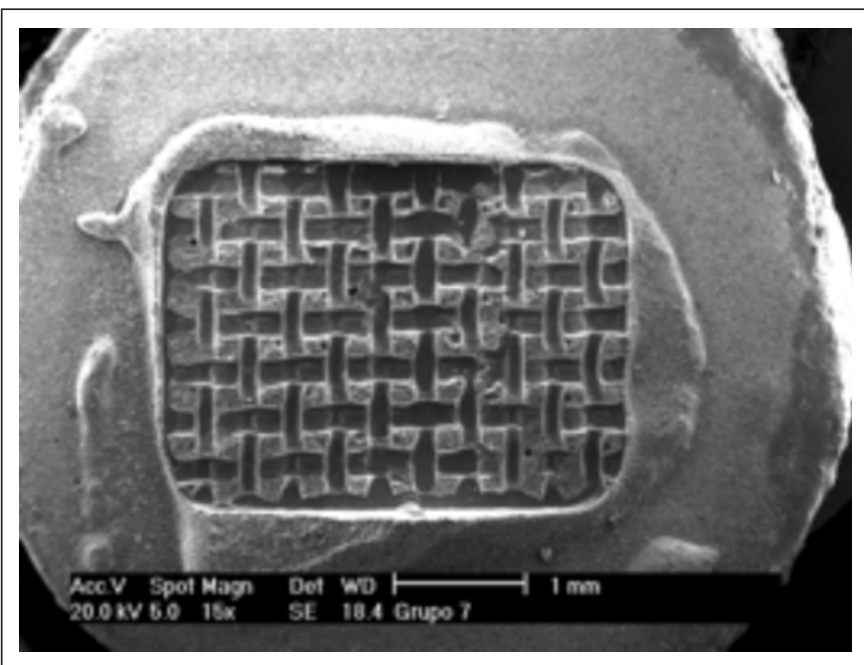

Fig. 4. Fracture pattern in G7 and G8 after shear test (Adhesive cement/bracket)

MPa and G2 - $6.12 \mathrm{MPa}$ ). However, when it was combined with silane agent, the bond strength increased significantly (G3 - 17.49 MPa and G4- 19.54 MPa), corroborating previous findings ${ }^{12,15}$. The increase in bond strength could be due to silane capacity of increasing the energy on the substrate surface, optimizing resin penetration in the created microregions $^{5,12}$.

The groups treated with aluminum oxide blasting (50 ìm) followed by phosphoric acid etching $(35 \%)+$ silane agent, obtained values of $18.80 \mathrm{MPa}$ (G5) and $21.93 \mathrm{MPa}$ (G6), and did not differ significantly from groups treated with hydrofluoric acid + silane agent (G3 and G4). These findings agree with those of recent studies ${ }^{2-3,6,16-17}$. A possible explanation could be the fact the impact produced by this treatment raises temperature locally, causing an incorporation of particles up to 15 ìm from ceramic structure ${ }^{18}$, which increases surface roughness and makes it more retentive ${ }^{18-19}$ and receptive to the chemical bond with silane agent ${ }^{20}$.

G7 (6.81 MPa) and G8 (9.77 MPa) bond strength means were significantly lower than those of G3-G6, and similar to those of G1 and G2. It is possible that the micro-retentions generated by CoJet system, whose particles are 30 ìm in size, could be lower than those created by the aluminum oxide blasting (50 ìm particles). These findings agree with Girish et al. ${ }^{21}$ (2012), who reported that blasting with larger particles (110 ìm) produced higher bond strength values than those found with CoJet. Ozcann ${ }^{22}$ (2014), who evaluated the CoJet in ceramic, metal-ceramics, metal-mechanics and metallic substrates, achieved the best results with metallic substrates. According to Wady et al. ${ }^{20}$ (2014), the efficiency of CoJet depends on the mechanical properties of the ceramic, working better in leucite-based ceramics than is feldspathic ones.

On the other hand, Passos et al. ${ }^{23}$ (2013) reported bond strength of $13.2 \mathrm{MPa}$ after $37 \%$ phosphoric acid etching of enamel for $60 \mathrm{~s}$. Zhang et al. ${ }^{4}$ (2013) disagree with this values theretofore considered adequate clinically by Silveira et al. ${ }^{24}$ (2014). Based on the results of bracket bond to ceramic, there is a common sense to use Vijayakumar ${ }^{25}$ (2014) findings as a reference to indicate the best pretreatment to be performed or at least the one that produces the closest to values obtained in enamel. This author suggested that the appropriate bond strength values to enamel bracket be 6-8 $\mathrm{MPa}$. Therefore, in the present study, all treatments produced adequate values (G1 - 7.30; G2 - 6.12; G3 - 17.49; G4 19.54; G5 - 18.80; G6 - 21.93; G7 - 6.81 and G8 - 9.77 $\mathrm{MPa})$.

According to the classification used in this study for analysis of fracture patterns, it is possible to observe that G1 and G2 presented exclusively (100\%) adhesive failures on ceramic/cement interface. This suggests that the bond strength between cement and ceramic was weak (G1 - 7.30 MPa and G2 - 6.12 MPa), according to findings by $\mathrm{Okuda}^{3}$ (2014). Statistically similar, G7 (6.81 MPa) and G8 $(9.77 \mathrm{MPa})$, also presented prevalence of adhesive failures; however, they occurred in the cement/bracket interface $193.33 \%$ and $100 \%$, respectively), which denotes more effectiveness in the treatment of the surface. In G3 and G5, the treatment was hydrofluoric acid application and silane agent. It was observed that the bond performance was different between the ceramics: it was predominantly adhesive in ceramic/ cement $(60 \%)$ interface in d.Sign and mixed in cement/ bracket $(53.33 \%)$ interface in Eris. G5 and G6 were also statistically similar (18.80 and $21.93 \mathrm{MPa}$, respectively), with prevalence of mixed fails (cement/bracket/ceramic), G7 (60\%) and G8 $(66.66 \%)$.

Comparing the bond strength values and fracture patterns obtained in this study, it may be observed that despite the significant correlation $(\mathrm{R}=0.372 ; \mathrm{p}<0.0001)$, a tendency could be identified that the higher bond strength, the higher the fracture scores; in other words, higher quantity of fractures on the ceramic. This led the authors to believe that the higher retention created by the pre-treatment, more severe can be the structural damage, according to the findings by Grewal Bach $^{2}$ (2014), Gavake et al..$^{5}$ (2013), Lung et al. ${ }^{6}(2015)$, Kumar et al. ${ }^{26}$ (2014) and Okuda ${ }^{3}$ (2014).

Further research should be done including thermal and mechanical cycling treatment as well the ideal strength to avoid the bracket displacement damage to the ceramic structure. Based on data obtained in this study, it is possible to conclude that: (1) despite the different types of surface pretreatments, the tested ceramics performed similarly in therms of bond strength; (2) the use of silane after hydrofluoric acid etching was responsible for the increase of bond strength values; (3) pretreatment of ceramic substrate by $10 \%$ hydrofluoric acid etching during $20 \mathrm{~s}$ followed by silane application, as well as aluminum oxide (50 ìm) blasting for $15 \mathrm{~s}$, followed by $35 \%$ phosphoric acid etching and silane application provided significantly higher bond strength values to metallic brackets; (4) the CoJet system did not result in significantly higher values than those observed for aluminum oxide blasting, becoming similar to the groups treated with hydrofluoric acid without silane application; (5) aluminum oxide blasting followed by phosphoric acid etching and silane presented results similar to the treatment with hydrofluoric acid and silane. 


\section{References}

1. Komori A, Takemoto K, Shimoda T, Miyashita W, Scuzzo G. Precise direct lingual bonding with the KommonBase. J Clin Orthod. 2013; 47: 42-9.

2. Grewal Bach GK, Torrealba $Y$, Lagravère MO. Orthodontic bonding to porcelain: a systematic review. Angle Orthod. 2014; 84: 555-60.

3. Okuda W. Predictable replacement of failing porcelain restorations. Gen Dent. 2014; 62: 21-3.

4. Zhang ZC, Giordano R, Shen G, Chou LL, Qian YF. Shear bond strength of an experimental composite bracket. J Orofac Orthop. 2013; 74: 31931.

5. Gayake PV, Chitko SS, Sutrave N, Gaikwad PM. The direct way of indirect bonding —-the combined effect. Int J Orthod Milwaukee. 2013; 24: 15-7.

6. Lung CY, Liu D, Matinlinna JP. Silica coating of zirconia by silicon nitride hydrolysis on adhesion promotion of resin to zirconia. Mater Sci Eng C Mater Biol Appl. 2015; 46: 103-10.

7. Buonocore MG. A simple method of increasing the adhesion of acrylic filling materials to enamel surfaces. J Dent Res. 1955; 34: 849-53.

8. Trakyali G, Malkondu O, Kazazoðlu E, Arun T. Effects of different silanes and acid concentrations on bond strength of brackets to porcelain surfaces. Eur J Orthod. 2009; 31: 402-6.

9. Rathke A, Tymina Y, Haller B. Effect of different surface treatments on the composite-composite repair bond strength. Clin Oral Investig. 2009; 13 : 317-23.

10. Rao S, Chowdhary R. Comparison of fracture toughness of all-ceramic and metal-ceramic cement retained implant crowns: an in vitro study. J Indian Prosthodont Soc. 2014; 14: 408-14.

11. Bieniaœ J, Surowska B, Stoch A, Matraszek H, Walczak M. The influence of $\mathrm{SiO} 2$ and $\mathrm{SiO} 2-\mathrm{TiO} 2$ intermediate coatings on bond strength of titanium and Ti6Al4V alloy to dental porcelain. Dent Mater. 2009; 25: 1128-35.

12. Valentini F, Moraes RR, Pereira-Cenci T, Boscato N. Influence of glass particle size of resin cements on bonding to glass ceramic: SEM and bond strength evaluation. Microsc Res Tech. 2014; 77: 363-7.

13. Geraldo-Martins VR, Lepri CP, Faraoni-Romano JJ, Palma-Dibb RG. The combined use of Er,Cr: YSGG laser and fluoride to prevent root dentin demineralization. J Appl Oral Sci. 2014; 22: 459-64.

14. Vaz RR, Hipolito VD, D'Alpino PH. Bond strength and interfacial micromorphology of etch-and-rinse and self-adhesive resin cements to dentin. J Prosthodont. 2012; 21: 101-11.

15. Kim JH, Chae S, Lee Y, Han GJ, Cho BH. Comparison of shear test methods for evaluating the bond strength of resin cement to zirconia ceramic. Acta Odontol Scand. 2014; 72: 745-52.

16. Brunharo IH, Fernandes DJ, de Miranda MS, Artese F. Influence of surface treatment on shear bond strength of orthodontic brackets. Dental Press J Orthod. 2013; 18: 54-62.

17. Denry I, Kelly JR. Emerging Ceramic-based Materials for Dentistry. J Dent Res. 2014; 93: 1235-42.

18. Kosyfaki P, Swain MV. Adhesion determination of dental porcelain to zirconia using the Schwickerath test: strength vs. fracture energy approach. Acta Biomater. 2014; 10: 4861-9.

19. Bunek SS, Swift EJ Jr. Contemporary ceramics and cements. J Esthet Restor Dent. 2014; 26: 297-301.

20. Wady AF, Paleari AG, Queiroz TP, Margonar R. Repair technique for fractured implant-supported metal-ceramic restorations: a clinical report. J Oral Implantol. 2014; 40: 589-92.

21. Girish PV, Dinesh U, Bhat CS, Shetty PC. Comparison of shear bond strength of metal brackets bonded to porcelain surface using different surface conditioning methods: an in vitro study. J Contemp Dent Pract. 2012; 13: 487-93.

22. Ozcan M. Surface conditioning protocol for multiple substrates in repair of cervical recessions adjacent to ceramic. J Adhes Dent. 2014; 16: 394.
23. Passos SP, Kimpara ET, Bottino MA, Júnior GC, Rizkalla AS. Bond strength of different resin cement and ceramic shades bonded to dentin. J Adhes Dent. 2013; 15: 461-6.

24. Silveira GS, Bittencourt LP, Mucha JN. Scoring of ceramic bracket bases for easier debonding. J Clin Orthod. 2014; 48: 441-2.

25. Vijayakumar RK, Jagadeep R, Ahamed F, Kanna A, Suresh K. How and why of orthodontic bond failures: An in vivo study. J Pharm Bioallied Sci. 2014; 6: 85-9.

26. Kumar M, Maheshwari A, Lall R, Navit P, Singh R, Navit S. Comparative evaluation of shear bond strength of recycled brackets using different methods: an in vitro study. J Int Oral Health. 2014; 6: 5-11. 